\title{
Lugares geoeducativos da cidade de Caçapava do Sul (RS) para estudo de Geologia no ensino médio
}

\author{
Geo-educational places in the city of Caçapava do Sul (RS) for studying Geology in high School
}

\author{
Cristiane Heredia Gomes ${ }^{1}$, Diogo Gabriel Sperandio², Natália Pinheiro Borges³ ${ }^{3}$ Dimitri Tallemberg Soares ${ }^{3}$, Gabriel Smith Nunes da Silva ${ }^{3}$, Guilherme \\ Pazinato Dias ${ }^{3}$ \\ 1 - Laboratório de Mineralogia e Petrografia, Universidade Federal do Pampa (Unipampa). 96570-000, Caçapava do Sul, RS, Brasil \\ 2 - Doutorando do Programa de Pós-Graduação em Geologia, Universidade Federal de Minas Gerais, Minas Gerais, Brasil \\ 3 - Graduando em Geologia, Universidade Federal do Pampa. 96570-000, Caçapava do Sul, RS, Brasil,

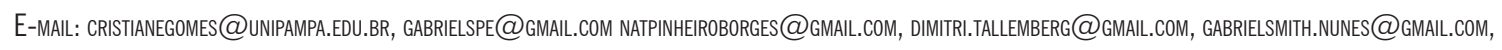 \\ GUI.PAZINATO.DIAS@GMAIL.COM
}

\begin{abstract}
This article aims to describe experiences obtained from practical activities involving high school students, Geology students, and their professors. The main objective of these activities was to select and investigate places of geological interest for educational purposes, in the city of Caçapava do Sul-RS, as a teaching-learning proposal. The observation and selection of places started with the debate regarding Geology and daily life. Places that were close to the school were selected, to facilitate class mobility, the safety of those involved, and time availability. After five meetings, subjects such as the rock cycle, the geology of the city, daily life, and digital and written registration techniques were addressed. The students' effective participation was well distributed throughout the meetings. The engagement during the activities was positive, in addition to the improvement in learning "how to know", "how to do", "how to live" and "how to be" of the students in the proposed activity.
\end{abstract}

Resumo: Este artigo tem como objetivo descrever vivências obtidas a partir de atividades práticas envolvendo educandos do Ensino Médio, discentes do Curso de Geologia e seus educadores. 0 objetivo principal dessas atividades foi a seleção e investigação de lugares de interesse geológico com fins didáticos na cidade de Caçapava do Sul, RS, como proposta de ensino-aprendizagem. A observação e seleção dos lugares iniciou com a combinação de desenvolver debates sobre Geologia e cotidiano. Foram selecionados aqueles que estivessem próximos da escola para facilitar a mobilidade das turmas, segurança dos envolvidos e disponibilidade de tempo. Após cinco encontros, onde foi dialogado sobre 0 ciclo das rochas, Geologia da cidade, cotidiano e técnicas de registro digital e escrito. A participação e envolvimento efetivo dos educandos foi bem distribuída ao longo dos encontros. 0 engajamento durante as atividades foi positivo, 0 aprimoramento do aprender a conhecer, a fazer, a viver e a ser dos educandos nas atividades propostas.

\section{Introdução}

A Geologia, em um aspecto geral, tem como objetivo instigar a compreensão do funcionamento do Planeta Terra, com todas as suas peculiaridades. Essa compreensão para o educando do ensino médio está profundamente alicerçada naquilo que estabelecem os Parâmetros Curriculares Nacionais (PCN) (Brasil, 2000):

(...) desenvolver valores e competências necessárias à integração de seu projeto individual ao projeto da sociedade em que se situa (PCN Brasil, 2000, p. 10

Um dos objetivos básicos da prática do estudo em Geologia nas escolas é fazer com que o educan-
Citation/Citação: Gomes, C. H., Sperandio, D. G., Borges, N. P., Soares, D. T., da Silva, N. G. S., \& Dias, G. P. (2020). Lugares geoeducativos da cidade de Caçapava do Sul (RS) para estudo de Geologia no ensino médio. Terræ Didatica, 16, 1-8, e020032. doi: 10.20396/td.v16i0.8658837

Keywords: Geosites. Urbanization. Teaching. Learning. Urban Geology.

Palavras-chave: Geosítios. Urbanização. Ensino. Aprender. Geologia Urbana.

Manuscript/Manuscrito:

Received/Recebido: 25/03/2020

Revised/Corrigido: 25/05/2020

Accepted/Aceito: 26/06/2020

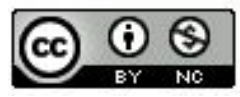

do perceba os aspectos geológicos no seu cotidiano, por exemplo, no calçamento, nos paralelepípedos, monumentos e etc. Assim, direcionar respostas aos desafios refletidos, principalmente na urbanização, e nos recursos e riscos geológicos. Isto propiciaria introduzir as questões relacionadas a locais geoeducativos no ambiente urbano, visto que a maior parte da população se concentra em cidades (Liccardo et al., 2012). Para Martello et al. (2015) as barreiras do ensino de Geologia nas escolas podem ser revertidas a partir de uma maior divulgação de práticas de estudos geológicos das universidades para as escolas.

Parâmetros Curriculares Nacionais (PCN) de Ciências da Natureza (Brasil, 1998) sugerem, no eixo temático Terra e Universo, que sejam abor- 
dados conceitos relacionados ao universo e sua influência sobre a Terra, tais como:

A estrutura interna da Terra é também dinâmica... Portanto, as paisagens, tal como são percebidas, representam apenas um momento dentro do longo e contínuo processo de transformação pelo qual passa a Terra, em uma escala de tempo de muitos milhares, milhões e bilhões de anos... (PCN Brasil, 1998, p.41).

Lugares geoeducativos nos centros urbanos promovem de forma específica o contato e o interesse pela Geologia por parte do educando, constituindo recurso básico para este fim. Isto reforça a função do educador de apresentar o conteúdo de forma simples e descomplicada. Diversos autores têm aplicado metodologias para implementar este tipo de atividade, como por exemplo, em São Paulo, SP; no Rio de Janeiro, RJ; e Natal, RN (Del Lama et al., 2015, Silva \& Mansur, 2017, Nascimento et al., 2018, Pagel et al., 2015, Gutiérrez et al., 2016, Gomes et al., 2017, Silva et al., 2017).

Não obstante, o sistema educativo brasileiro atual não promove a prática da teoria em sua essência. Ademais, a maior parte das escolas e das famílias dos educandos é desprovida de auxílio financeiro para gastos adicionais com aulas práticas, quer para implementação de espaços físicos nas escolas destinados a este fim, quer para viagens extraescolares para visitação de sítios geológicos in situ. Neste sentido, os mais afetados são os educandos de centros urbanos e aqueles de escolas estaduais e municipais.

Neste cenário, o educador tem uma tarefa difícil para mostrar a complexidade e amplitude do estudo da Geologia na disciplina de Ciências da Natureza, causando, assim, um conhecimento superficial absorvido pelo educando que pode conduzi-lo a um desinteresse sobre o assunto exposto pelo educador. Como consequência, ocorre esquecimento do assunto pelo educando, contrariando as orientações do PCN do Ensino Médio (Brasil, 2000), que sugere contemplar os quatro eixos estruturais da educação:

Aprender a conhecer - ... domínio dos próprios instrumentos do conhecimento, compreendendo a complexidade do mundo ... Esse saber favorece o desenvolvimento da curiosidade intelectual, estimula o senso crítico e permite compreender o real, mediante a aquisição da autonomia na capacidade de discernir; Aprender a fazer - ... deve-se privilegiar a aplica- ção da teoria na prática e enriquecer a vivência da ciência na tecnologia e destas no social, o que faz com que surja uma significação especial no desenvolvimento da sociedade contemporânea; Aprendera viver - ... aprender a viver juntos, desenvolvendo o conhecimento do outro e a percepção das interdependências, de modo a permitir a realização de projetos comuns ou a gestão inteligente dos conflitos inevitáveis por meio do diálogo; Aprender a ser - ... elaborar pensamentos autônomos e críticos e para formular os seus próprios juízos de valor, de modo a poder decidir por si mesmo, frente às diferentes circunstâncias da vida. ... exercitar a liberdade de pensamento, discernimento, sentimento e imaginação para desenvolver os seus talentos e permanecer, tanto quanto possível, dono do seu próprio destino (PCN Brasil, 2000, p. 15).

Para contornar essa situação, é importante que o educador opte por alternativas de ensino para significação dos conhecimentos científicos para os educandos. Ainda assim, embora os recursos não sejam os ideais, através do espaço urbano é possível aprender sobre Geologia, pois os materiais que constituem uma cidade constituem-se como inúmeros locais geoeducativos. O conhecimento e entendimento sobre locais geoeducativos constitui a valorização e interpretação da geologia de uma cidade, despertando na sociedade o sentimento de soberania nacional sobre seus recursos naturais. No Brasil, os trabalhos em Geologia Urbana são recentes (Rodriguez, 1998, Pereira et al., 2011, Culshaw \& Price ,2018), mas em outros países, como por exemplo na Espanha, esse tipo de prática de ensino vem proliferando desde os anos 80 (Anguita, 1988, Bach \& Brusi, 1989, Corbí et al., 2003, Alonso \& Díez, 2007, Fernández-Martínez et al., 2012). Tais projetos definem um novo nicho na geoeducação, nos quais não compreendem apenas o ensino formal de Geociências, mas um campo de saberes que envolve dados empíricos e experiências práticas.

Portanto, a investigação de locais geoeducativos deve ser interpretada como um conjunto de conhecimentos e saberes. Conforme Figueiró et al. (2019, p. 172) "a geoeducação não pode ser interpretada apenas como ensino de conceitos ligados às Ciências da Terra [...] no sentido de prepara-los para interpretar e agir no seu território, em busca de melhores condições de vida e de manutenção do seu patrimônio coletivo."

Neste contexto, este artigo descreve as vivências obtidas a partir de atividades práticas envolvendo 
locais geoeducativos, educandos do Ensino Médio, discentes do Curso de Geologia e seus educadores (escola e universidade), em Caçapava do Sul-RS, com o objetivo de formar cidadãos críticos e questionadores, bem como desenvolver habilidades de aprender a conhecer, a fazer, a viver e a ser, proporcionando-lhes instrumentos necessários para que estejam aptos a continuar o processo de autoconstrução intelectual.

\section{Metodologia}

Este trabalho foi desenvolvido em Caçapava do Sul, localizada na porção central do estado do RS, a qual é considerada a "Capital Gaúcha da Geodiversidade ${ }^{1}$. O trabalho contou com o auxílio de professores da Escola Estadual Dinarte Ribeiro (E. E. Dinarte Ribeiro) participantes e colaboradores do Projeto "Museu Virtual Geológico do Pampa". Foram realizadas duas etapas diferenciadas: 1) observação e seleção de locais com interesse geoeducativo na cidade de Caçapava do Sul e; 2) Execução da atividade com alunos do Ensino Médio. A atividade foi desenvolvida com duas turmas de 25 educandos cada uma. Os alunos participantes estão no segundo ano do ensino médio da E. E. Dinarte Ribeiro.

A observação e seleção dos lugares teve início com a combinação de desenvolver debates sobre Geologia e cotidiano. Nesse sentido, foram observados diversos locais, dos quais se optou pela seleção daqueles que estivessem nas proximidades da escola para facilitar o deslocamento das turmas, segurança dos envolvidos e disponibilidade de tempo (ida e volta) durante as atividades. Uma vez selecionados os lugares, foram propostos cinco encontros de $50 \mathrm{~min}$. para cada turma de educandos realizados as terças e quintas no período da manhã de 2017. A descrição de cada encontro com ambas as turmas é apresentada em conjunto a seguir:

$\mathrm{O} 1^{\circ}$ encontro ocorreu em sala de aula. Nesse encontro, foi apresentado de forma simples pelos discentes do Curso de Geologia da Universidade Federal do Pampa (Unipampa), supervisionados pela profa. Dra. Cristiane Heredia Gomes, aspectos acerca do ciclo das rochas e sobre a Geologia da cidade de Caçapava do Sul, RS. A fim de que os educandos aprendessem a conhecer, voltada ao desenvolvimento da curiosidade intelectual, estimula o senso crítico e permite compreender

1 Lei Ordinária Estadual 14.708/2015 - publicada no DOE n. ${ }^{\circ} 134$, de 16 de julho de 2015. o real, foram apresentadas algumas amostras de rochas do acervo da universidade que, também, estão disponíveis digitalmente no website: https:// sites.unipampa.edu.br/mvgp/ Neste sentido, os educandos puderam conhecer as características que diferenciam uma rocha da outra. Ao final desse encontro foi explicado pelos discentes como funcionaria a atividade prática do próximo encontro, ou seja, horário de saída da escola e material necessário (caderno, caneta, lápis, borracha, régua, máquina fotográfica ou semelhante, etc.) para o melhor aproveitamento da observação do $1^{\circ}$ local geoeducativo.

$\mathrm{O} 2^{\circ}$ encontro foi realizado em um dos locais geoeducativos previamente selecionados pelos discentes. O primeiro local foi a calçada em frente à E. E. Dinarte Ribeiro (Figura 1). Neste local, os educandos puderam aprender a fazer, ou seja, a aplicação da teoria na prática. Os educandos foram questionados sobre:

- Qual rocha foi utilizada no calçamento?

- Como foi o processo de formação da rocha?

- Quais minerais formam essa rocha?

Após, os educandos foram orientados a treinar as técnicas de fotografia para registro digital da rocha observada. Além de replicarem as informações obtidas no caderno como forma de registro escrito das observações sobre a rocha. Neste sentido, uma maneira de aprender a viver uma experiência cotidiana de um profissional de Geologia.

$\mathrm{O} 3^{\circ}$ encontro foi realizado no segundo local geoeducativo previamente selecionado pelos discente, os paralelepípedos da rua lateral a E. E. Dinarte Ribeiro (Fig. 1). Como no $2^{\circ}$ encontro, os educandos foram novamente questionados, sendo utilizados os mesmos questionamentos do

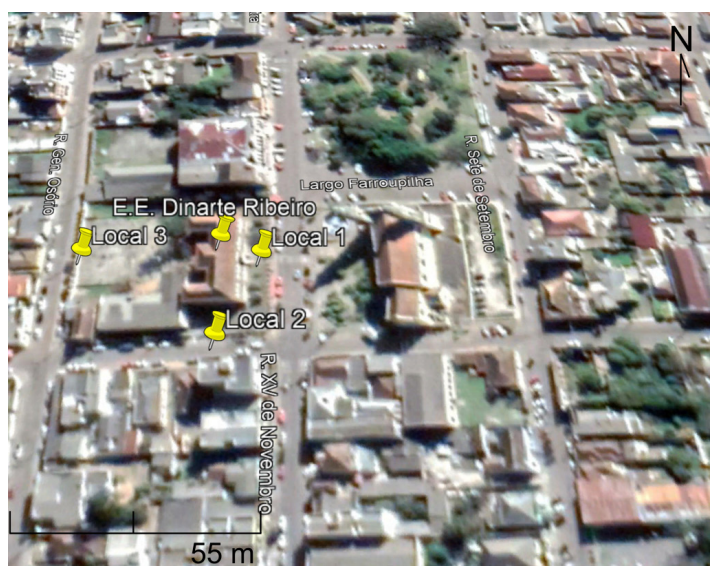

Figura 1. Mapa de localização da escola a partir de imagem Google Earth 
segundo encontro visto que a rocha dos paralelepípedos é diferente da rocha do calçamento. Foram, também, orientados a registrar digitalmente o local geoeducativo e as informações relativas a esse local no caderno.

$\mathrm{O} 4^{\circ}$ encontro foi realizado no terceiro local geoeducativo previamente selecionado pelos discentes, uma rua atrás da E. E. Dinarte Ribeiro (Fig. 1). Nesse local, os educandos foram orientados sobre a morfologia do local. A cidade de Caçapava do Sul, RS, se localiza em um alto topográfico ( $~ 500 \mathrm{~m}$ acima do nível do mar). A E. E. Dinarte Ribeiro está situada em um dos pontos mais elevados da cidade (Fig. 2). Assim, no decorrer da observação do relevo, os educandos foram instruídos sobre os aspectos históricos e culturais da Geologia Ambiental.

$\mathrm{O} 5^{\circ}$ e último encontro foi realizado em sala de aula. Nesse encontro, foi proposto pelos discentes uma discussão com os educandos sobre as atividades realizadas nos locais geoeducativos. De forma a organizar a última atividade, os educandos foram divididos em quatro grupos de sete educandos cada. Cada grupo deveria preparar uma pequena apresentação de no máximo 10min sobre as observações realizadas durante os encontros anteriores. Após as apresentações dos grupos, os educandos foram articulados a comparar todos os resultados apresentados. A discussão final conduziu ao aprender a ser, cujo sentido é refletido no elaborar pensamentos autônomos e críticos além de exercitar a liberdade de pensamento e discernimento.

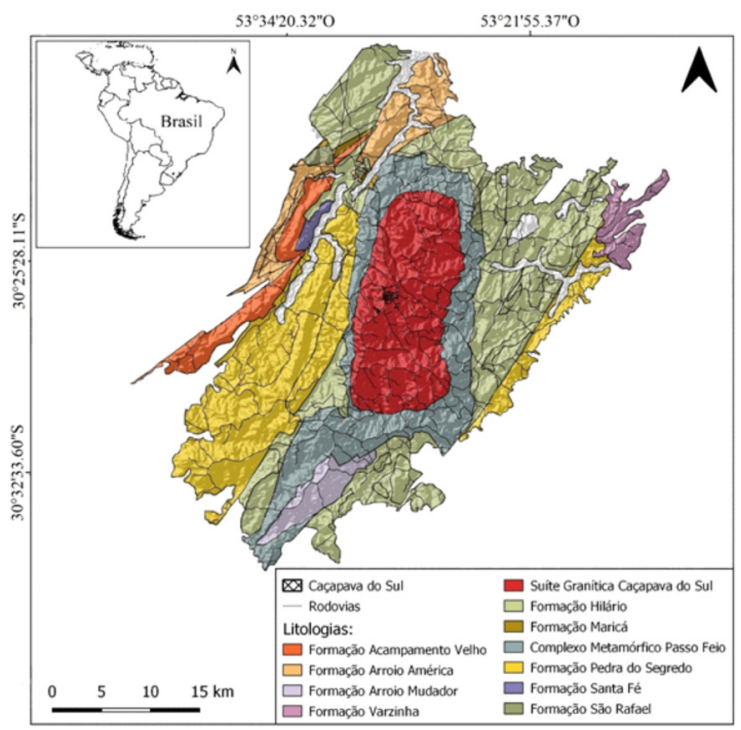

Figura 2. Mapa geológico da região de Caçapava do Sul e sua localização no Estado do Rio Grande do Sul

\section{Resultados}

A partir da proposta implementada, foi perceptível o crescimento da interação ao longo dos cinco encontros entre os educandos do ensino médio da E. E. Dinarte Ribeiro com os discentes do Curso de Geologia da Unipampa.

No primeiro encontro, referente ao ciclo das rochas e a Geologia da cidade, os educandos estavam apreensivos quanto as atividades propostas. Eles se demonstraram tímidos em fazer questionamentos e interagir com a explanação teórica. Reschly \& Chistenson (2005) destaca que o comportamento e as ações dos educandos são influenciados pela motivação, sendo essa motivação um balizador do engajamento dos educandos diante das situações. Assim, o educando estará mais ou menos motivado, ou mais ou menos engajado dependendo da relação entre indivíduo e atividade no contexto de ensino.

A partir da metade para o final desse primeiro encontro, quando os discentes iniciaram a contextualização geológica com base nas amostras de rocha, os educandos iniciaram o processo de participação ativa com interação e engajamento na análise das amostras e suas origens na cidade de Caçapava do Sul, RS. A fluidez na comunicação compartilhada alavancou diálogos sobre pontos de convergência entre a teoria geológica e o cotidiano dos educandos. Neste sentido, surgiram aspectos importantes sobre o uso de rochas e minerais na vida cotidiana (Regueiro, 2008), a dependência das atividades humanas nos materiais extraídos da natureza e a necessidade de conservar o patrimônio geológico. Sobre este encontro os alunos relataram as seguintes observações:

\footnotetext{
"Então, as rochas se reciclam?"

"Não sabia que a pedra embaixo de nossa cidade tinha esse nome"

"Não tinha conhecimento sobre a importância geológica da nossa cidade"
}

No segundo encontro, referente ao primeiro local geoeducativo, alguns educandos tiveram dificuldades em associar o conteúdo teórico à prática realizada. O local é a calçada localizada em frente à E. E. Dinarte Ribeiro. A calçada foi construída com placas de mica xisto. O xisto é uma rocha metamórfica com estrutura xistosa bem desenvolvida com orientação preferencial dos minerais inequidimensionais, de granulação média a grossa, rico em filossilicatos e pobre em quartzo e feldspato (Fettes 
\& Desmons2014). Quando chegaram ao local selecionado, os discentes pediram para os educandos observarem a rocha do calçamento. Depois disso, pediram aos educandos que falassem o nome da rocha, o grande grupo dessa rocha e contassem a história de formação da rocha com base no que foi exposto no primeiro encontro.

Sobre esse diálogo, os alunos relataram:

$$
\begin{aligned}
& \text { "É uma rocha sedimentar, por apresentar um } \\
& \text { tipo de grão" } \\
& \text { "Com certeza é uma rocha metamórfica, porque } \\
& \text { parece que foi aquecida e modificada" } \\
& \text { "Não é um gnaisse, porque não tem listras" } \\
& \text { "Talvez seja um xisto, já que não é branca como } \\
& \text { o mármore" } \\
& \text { "Se fosse uma sedimentar seria áspera ao toque, } \\
& \text { o que ela não é" } \\
& \text { "Era uma rocha que foi aquecida e um pouqui- } \\
& \text { nho apertada" }
\end{aligned}
$$

Associamos a ausência de apropriação do conhecimento teórico e termos científicos ao caso dos educandos que não estabeleceram uma relação correta do tipo de rocha com sua origem e minerais formadores. Curiosamente, são aqueles que faltaram ao primeiro encontro ou dele não participaram ativamente. Diante disso, a inter-relação dinâmica do engajamento dos poucos educandos (aproximadamente cinco) estava em desarmonia. Fredricks et al. (2004) destacam que o engajamento comportamental está ligado à noção de participação e a ausência de comportamentos disruptivos, como por exemplo, faltar à escola. Ainda conforme Fredricks et al. (2004) o comportamento, a emoção e a cognição não são processos isolados da natureza multifacetada do engajamento escolar. Assim, aos cinco educandos foi sugerida uma leitura seletiva extraclasse do material que de fato interessa, relacionado diretamente às atividades como indicado por Salvador (1986).

É significativo ressaltar a importância da sintonia entre teoria e prática para que o educando obtenha o aproveitamento esperado no processo ensino-aprendizagem e consequentemente do aprender a fazer (PCN Brasil, 2000, p. 15).

No decorrer da atividade, grande parte dos educandos participaram fazendo questionamentos e todos mostraram-se curiosos com a observação da rocha do calçamento. Destacamos que uma prática dialógica interativa favorece aos educandos e discentes de Geologia uma participação efetiva (Santolin \& Brandenburg 2013). A estratégia se

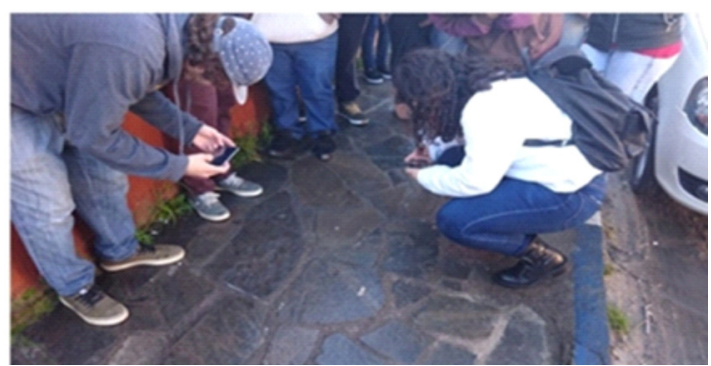

Figura 3. Educandos da escola Dinarte Ribeiro fazendo os registros digitais e escritos de um local Geoeducativo

mostrou importante instrumento para a construção do conhecimento teórico das crianças, corroborando os estudos de Possobom; Okada \& Diniz (2003), que perceberam que as atividades práticas permitem que as crianças construam habilidades para atingir resultado satisfatório.

A Figura 3 apresenta os educandos em um dos momentos de registro digital e escrito do local Geoeducativo referente ao segundo encontro.

No terceiro e quarto encontro, referentes aos segundo e terceiros locais geoeducativos, os educandos mostraram-se mais seguros para fazer questionamentos e responder às questões que envolviam Geociências e cotidiano. O segundo local geoeducativo foram os paralelepípedos da rua lateral à E. E. Dinarte Ribeiro. Os paralelepípedos são blocos do Granito Caçapava do Sul. O granito é uma rocha ígnea plutônica composta por quartzo, feldspato alcalino e plagioclásio com uma quantidade variável de biotita e hornblenda (Le Maitre, 2002). O terceiro local geoeducativo foi a observação do relevo da cidade, uma vez que que as formas do relevo muitas vezes permitem reconhecer preliminarmente o tipo de rocha e as estruturas geológicas que ocorrem na região. A Geomorfologia é a ciência que estuda as formas da superfície do planeta Terra e permite entender as relações entre a dinâmica interna e externa, evoluções climáticas e movimentos tectônicos recentes.

Percebeu-se que, a partir dos encontros, os educandos deixaram claro o entendimento, mesmo que básico, e a confiança ao falarem sobre a atividade, o que revela que a atividade foi interessante para os educandos (Carvalho, 1980).

Nesses encontros, os alunos relataram:

"Como as rochas são extraídas da natureza?" "Por que uma rocha é mais dura que a outra?" "Por que as rochas têm coloração diferentes?" "A observação das rochas é um trabalho do geólogo?” 
"Como o geólogo sabe que rocha é melhor para o quê?"

"Os geólogos estudam somente as rochas para saber onde utilizá-las na construção de uma cidade?"

"Embaixo das lavouras têm rocha?"

"Os relevos estão relacionados com os tipos de rochas?"

"Rochas mais resistentes formam relevos mais acentuados, enquanto que rochas que sofrem mais erosão formam relevos suaves"

No quinto encontro, em relação à prática pedagógica dialógica em sala de aula, os grupos de educandos apresentaram suas hipóteses formuladas com base nos registros digitais e escritos referentes aos locais geoeducativos visitados e observados.

A articulação da prática, mesmo que em sala de aula, desloca o papel de protagonista do educador ou do discente/monitor do centro das atividades para a iniciativa do educando no processo de ensino-aprendizagem. Assim, o educando se apropria de seu processo de aprendizagem e atribui valor a seu engajamento na realização da atividade proposta, o que corrobora com os aspectos destacados no PCN (Brasil 2000) quando revelam o aprender a viver, conhecer e ser.

No quinto encontro, percebemos a capacidade dos educandos em construir hipóteses para explicarem a relação da Geologia da cidade e dos locais geoeducativos estudados. Além disso, a utilização de vários recursos didáticos tecnológicos permite uma maior participação e atuação dos educandos. Neste sentido, destaca-se Pereira \& Silva (2012), que diz "a utilização de softwares como o Google Earth pode despertar o interesse dos alunos para diversas temáticas". O Mapa Geológico Interativo desenvolvido pelo MVGP é uma excelente proposta de utilização deste recurso para práticas de ensino-extensionistas em Geologia (Sperandio, Gomes \& Viçozzi, 2020).

Sendo assim, de acordo com Grebogi \& Frick (2014, p. 18), a ferramenta Google Earth é:

Inserir essa nova tecnologia no processo de ensino aprendizagem é fundamental e desafiador ao mesmo tempo. A visualização de imagens reais facilita muito mais a interpretação do espaço, tornando o ensino mais concreto.

Corroborando com esta ideia, Sperandio, Gomes e Viçozzi (2020) destacaram a união das Tecnologias da Informação e Comunicação em atividades de ensino-extensionistas em Ciências:
O Mapa Geológico Interativo evidencia as TIC como verdadeira oficina experimental para ensino de Ciências em todas as áreas do conhecimento, evidenciando sua capacidade de interagir e comunicar, sob as mais variadas perspectivas de educação informal e, também, não-formal.

De maneira geral, em nossa experiência pedagógica foi possível perceber que os educandos se mostraram mais participativos e interessados durante as atividades práticas (Sereia \& Piranha 2010). O engajamento dos educandos durante todo o processo das atividades propostas foi positivo. Destacamos aqui, a participação e envolvimento efetivo bem distribuído de todos, incluindo aqueles educandos que tiveram dificuldades no conhecimento teórico e termos científicos durante o segundo encontro.

Diante dos resultados obtidos ficou clara a interação e o estímulo fomentadas pelas atividades práticas propostas nos educandos, principalmente quando são abordados assuntos entre Geologia e Cotidiano. Tais atividades auxiliam no aprimoramento do aprender a conhecer, a fazer, a viver e a ser do educando.

\section{Considerações Finais}

Este estudo apresentou relatos da aplicação de atividades práticas envolvendo educandos do ensino médio, discentes do Curso de Geologia e seus educadores (escola e universidade) como proposta de ensino-aprendizagem. Ao longo das atividades observamos a evolução do conhecimento teórico e absorção de termos científicos dos educandos sobre a Geologia dos locais geoeducativos visitados e sua relação no cotidiano dos educandos, para que, com o conhecimento geológico, o educando pudesse debatê-lo e, no futuro, conservar o patrimônio geológico. Como resultado, por meio das atividades práticas, verificamos o engajamento positivo dos educandos a partir do crescente desenvolvimento da autonomia na capacidade de discernimento, da aplicação da teoria na prática, da construção e realização de projetos comuns, e de serem donos de seus próprios destinos.

Nessa abordagem, o processo de ensino-aprendizagem dos alunos foi claro e perceptível quando o educador e o educando trocaram de papéis, o educando aprendeu ao passo que ensinou e o educador ensinou e aprendeu com aquele outro. A proposta de ensino-aprendizagem por meio de atividades práticas voltadas à Geologia de locais 
geoeducativos na cidade de Caçapava do Sul, RS, promoveu o diálogo entre conteúdos únicos, como por exemplo, vivências, histórias e individualidade de cada um que participou das atividades.

\section{Agradecimentos}

Os autores agradecem o suporte financeiro do Programa de Desenvolvimento Acadêmico (PDA-Unipampa) e do Conselho Nacional de Desenvolvimento Científico e Tecnológico (CNPq).

\section{Referências}

Alonso, A. J., \& Díez Herrero, A. (2007). Paseo geológico por los alrededores de la ciudad de Toledo. Toledo: Diputación de Toledo. 91p.

Anguita, F. (1988). Procesos geológicos en las ciudades. Una escuela de observación. Henares Revista de Geología, 2, 265-276. URL: https://eprints.ucm. es/34262/ Acesso 22.10.2018.

Bach, J., \& Brusi, D. (1989). Itinerari de Geologia urbana, Plaça de Catalunya-Museu de Geologia. Perspectiva Escolar. 118(10/1987). Barcelona. ICE da UAB. 20p.

Brasil. MEC. Secretaria de Educação Fundamental (SEF). (1998). PCN Parâmetros curriculares nacionais de Ciências da Natureza/ Secretaria de Educação Fundamental. Brasília: MEC/SEF, 1998. 136p. URL: http://portal.mec.gov.br/seb/arquivos/pdf/ciencias. pdf Acesso 15.10.2019

Brasil. MEC. Secretaria de Educação Fundamental (SEF). (2000). PCN Parâmetros curriculares nacionais no Ensino Médio/ Secretaria de Educação Fundamental. Brasília: MEC/SEF. 109p. URL: http://portal. mec.gov.br/seb/arquivos/pdf/blegais.pdf. Acesso 15.10.2019.

Carvalho, B. V. (1980). Literatura Infantil. Estudos. Porto Alegre: Ed. Lotus. 152p.

Corbí, H., Giannetti, A., Baeza-Carratalá, J. F., \& Martínez- Martínez, J. (2013). Elaboración de itinerarios geológicos como recurso didáctico en Ciencias de la Tierra. URL: http://rua.ua.es/dspace/handle/10045/31305 Acesso 02.04.2019.

Culshaw, M. G, \& Price, S. J. (2018). A Contribuição da Geologia Urbana ao Desenvolvimento, Recuperação e Conservação de Cidades. São Paulo: Martins Fontes. $138 \mathrm{p}$.

Del Lama, E. A., Bacci, D. L. C., Martins, L., Garcia, M. G. M., \& Dehira, L. K. (2015). Urban geotourism and the Old Centre of São Paulo city, Brazil. Geoheritage, 7, 147-164.

Fernández-Martínez, E., Barbadillo, P., Castaño de Luis, R., Marcos, A., Preciado, J. M., \& Serrano, E. (2012). Geoturismo en la ciudad de Burgos. Una guía de geologia urbana para todos los públicos. Ayuntamiento de Burgos: Burgos. 101p.

Fettes, D. \& Desmons, J. (2014). Rochas Metamórficas: classificação e glossário. Oficina de textos: São Paulo. 313p.

Fredricks, J. A., Blumenfeld, P. C., \& Paris, A. H. (2004). School Engagement: Potential of the Concept,
State of the Evidence. Review of Educational Research. 74(1): 59-109. URL: https://journals.sagepub.com/doi/pdf/10.3102/00346543074001059. Acesso 02.03.2020

Fuertes Gutiérrez, I., La Calzada Lorenzo, E. de., Llamas Martínez, T., Tejerina Fernández, Á., Crespo Fernández, M. Á., Pereiras López, L. Crespo Toral, T., Domínguez Valentín, L., Cabezas Lefler, L. (2016). Lugares de interés geoeducativo en el medio urbano: Potencialidad de las ciudades para la enseñanza de Geología. Enseñanza de Las Ciencias de La Terra, 24(2), 195-201. URL: https://www. raco.cat/index.php/ECT/article/view/312554. Acesso 09.07.2020.

Gomes, C. H., Dessart, R. L., Sperandio, D. G., Oliveira, J. G., Barroso, I., Xavier, C. F., \& Antunes, C. C. (2017). Praticando saberes e construindo ideias em Geociências. Rev. Conexão, 13, 110-119. doi: https://doi.org/10.5212/Rev.Conexao.v.13.i1.0008.

Grebogi, J. S. \& Frick, E. C. L. (2014). Explorando imagens do Google Earth para o ensino de geografia: estudo de caso no colégio estadual do campo Eunice Borges da Rocha - ens. fund. e médio. Cadernos PDE. 1, 1-20. URL: http://www.diaadiaeducacao. pr.gov.br/portals/cadernospde/pdebusca/producoes_pde/2014/2014_ufpr_geo_artigo_julia_salete grebogi.pdf. Acesso 25.06.2020.

Le Maitre, R. W. (2002). Igneous Rocks: A Classification and Glossary of Terms. Cambridge University Press: Cambridge. 236p.

Liccardo, A., Mantesso-Neto, V., \& Piekarz, G. F. (2012). Geoturismo Urbano: Educação e Cultura. Anuário do Instituto de Geociências UFRJ, 35(1), 133141. doi: $10.11137 / 20121133141$.

Martello, A. R., Novais, T., Oleques, L. C., Leal, L. A., \& Rosa, A. A. S. da. (2015). Uma experiência de inserção da paleontologia no ensino fundamental em diferentes regiões do Brasil. Terrae Didatica, 11(1), 33-41. doi: 10.20396/td.v11i1.8637308.

Nascimento, M. A. L., Silva, M. L. N., \& Bezerra, G. B. (2018). Presença da geodiversidade em itinerário geoturístico no centro histórico de Natal/RN (NE Brasil). Terra Plural, 12(2), 238-253. doi: 10.5212/ TerraPlural.v.12i2.0006.

Pagel, U. R., Campos, L. M., \& Batitucci, M. C. P. (2015). Metodologias e práticas docentes: uma reflexão acerca da contribuição das aulas práticas no processo de ensino aprendizagem de biologia. Experiências em Ensino de Ciências. 10(2), 14-25. URL: http://if.ufmt.br/eenci/artigos/Artigo_ID273/v10_ n2_a2015.pdf. Acesso 02.03.2020.

Pereira, J. S., \& Silva, R. G. S. O. (2012). Ensino da Geomorfologia na Educação Básica a partir do Cotidiano do Aluno e o Uso de Ferramentas Digitais como Recurso Didático. Revista de Ensino de Geografia. 3(4), 69-79. URL: http://www.revistaensinogeografia.ig.ufu.br/N.4/art5v3n4.pdf.

Pereira, S. Y., Gonçalves, P. W., \& Campos, H. C. N. S. (2011). Uma proposta prática de aprendizado para a disciplina de Geologia Urbana. Terrae Didatica, 7(1), 49-59. doi: 10.20396/td.v7i1.8637441.

Possobom, C. C. F., \& Okada, F. K., Diniz, R. E. S. (2003). Atividades práticas de laboratório no Ensino de Biologia e de Ciências: relato de uma experiência. In: Garcia W.G., \& Guedes A. M. (Eds.).

\begin{tabular}{c|c|c|c|c|c}
\hline (C) Terrae Didat. & Campinas, SP & v.16 & $1-8$ & $\mathrm{e} 020032$ & 2020 \\
\hline
\end{tabular}


(2003). Núcleos de ensino. São Paulo: Unesp. PróReitoria de Graduação. p. 113-123.

Regueiro, M. (2008). Los minerales industriales en la vida cotidiana. Enseñanza de las Ciencias de la Tierra, 16(3): 276-286. URL: https://www.raco.cat/index. $\mathrm{php} / \mathrm{ECT} / \mathrm{article} / \mathrm{view} / 164750 / 216755 \% 20$. Acesso 02.03.2019

Reschly, A. L., \& Chistenson, S. L. (2005). Jingle, Jangle, and Conceptual Haziness: Evolution and Future Directions of the Engagement Construct. In: Christenson, S. L., Reschly, A. L., \& Wylie, C. (Eds.). (2005). Handbook of Research on Student Engagement. New York, Dordrecht, Heidelberg, London: Springer. p. 3-19. URL: https://www. researchgate.net/profile/Azkananda_Widiasani/ publication/310773130_Handbook of Student Engagement/links/5836a 0dd08aed45931c772b7/ Handbook-of-Student-Engagement.pdf. Acesso 10.12.2018.

Rodriguez, S. K. (1998). Geologia urbana da região metropolitana de São Paulo. Tese (Doutorado), São Paulo, Instituto de Geociências, Universidade de São Paulo. doi: 10.11606/T.44.1998.tde-19112015093141.

Salvador, A. D. (1986). Métodos e técnicas de pesquisa bibliográfica. Porto Alegre: Sulina. 239p.

Santolin, A. S., \& Brandenburg, L. T. M. (2013). O Ensino da Biologia: Atividades Experimentais como Possi- bilidade de uma melhor Aprendizagem. URL: http:// www.diaadiaeducacao.pr.gov.br/portals/cadernospde/pdebusca/. Acesso 15.11.2019.

Sereia, D. A. de O., \& Piranha, M. M. (2010). Aulas práticas investigativas: um a experiência no ensino fundamental para a formação de alunos participativos. Secretaria Estadual de Educação do Estado do Paraná, SEED/PR. URL: http://www.diaadiaeducacao. pr.gov.br/diaadia/diadia/arquivos/File/conteudo/ artigos_teses/Ciencias/. Acesso 22.07.2018.

Silva, E. R. A., Marques, S. G., Perceval, V. O., \& Gomes, C. H. (2017). Utilização da abordagem temática em aulas de Ciências: relato de experiência em sala de aula. Experiências em Ensino de Ciências, 12(5), 293-301. URL: http://if.ufmt.br/eenci/ artigos/Artigo ID395/v12 n5 a2017.pdf. Acesso 22.07.2017.

Silva, R. G. P., \& Mansur, K. L. (2017). Proposta de roteiro para a prática de geoturismo urbano e para a geoeducação no centro da cidade do Rio de Janeiro. Anais do IV Simpósio Brasileiro de Patrimônio Geológico e II Encontro Luso-Brasileiro de Patrimônio Geomorfológico e Geoconservação. Ponta Grossa, Brasil. p. 482-486.

Sperandio, D. G., Gomes, C. H., \& Viçozzi, A. P. (2020). Mapa geológico interativo: proposta para ensino de Geociências. Terre Didatica, 16, 1-5, e020019. doi: 10.20396/td.v16i0.8658885. 